\title{
SCIENTIFIC REP RTS \\ OPEN Author Correction: Giant pandas can discriminate the emotions of human facial pictures
}

Youxu $\mathrm{Li}^{1,2}$, Qiang Dai ${ }^{3}$, Rong Hou ${ }^{1}$, Zhihe Zhang ${ }^{1}$, Peng Chen ${ }^{1}$, Rui Xue ${ }^{1}$, Feifei Feng ${ }^{1}$, Chao Chen ${ }^{1}$, Jiabin Liv $\mathbb{D}^{1}$, Xiaodong Gu ${ }^{4}$, Zejun Zhang ${ }^{2}$ \& Dunwu Qi ${ }^{1}$

Correction to: Scientific Reports https://doi.org/10.1038/s41598-017-08789-y, published online 16 August 2017

This Article contains an error in the Methods section under subheading 'Animals and treatments'

"All experimental procedures were approved by the Animal Care and Use Committee of the Chengdu Research Base of Giant Panda Breeding and were performed in accordance with its guidelines."

should read:

"All experimental procedures were approved by the Research Center and the Animal Husbandry Department of the Chengdu Research Base of Giant Panda Breeding and were performed in accordance with their guidelines and regulations."

(i) Open Access This article is licensed under a Creative Commons Attribution 4.0 International License, which permits use, sharing, adaptation, distribution and reproduction in any medium or format, as long as you give appropriate credit to the original author(s) and the source, provide a link to the Creative Commons license, and indicate if changes were made. The images or other third party material in this article are included in the article's Creative Commons license, unless indicated otherwise in a credit line to the material. If material is not included in the article's Creative Commons license and your intended use is not permitted by statutory regulation or exceeds the permitted use, you will need to obtain permission directly from the copyright holder. To view a copy of this license, visit http://creativecommons.org/licenses/by/4.0/.

(C) The Author(s) 2018

\footnotetext{
${ }^{1}$ Sichuan Key Laboratory of Conservation Biology for Endangered Wildlife, Chengdu Research Base of Giant Panda Breeding, Chengdu, Sichuan, 610081, China. ${ }^{2}$ Key Laboratory of Southwest China Wildlife Resources Conservation, China West Normal University, Nanchong, Sichuan, 637009, China. ${ }^{3}$ Chengdu Institute of Biology, Chinese Academy of Sciences, Chengdu, Sichuan, 610041, China. ${ }^{4}$ Wildlife Conservation Division, Forestry Department of Sichuan Province, Chengdu, Sichuan, 610000, China. Youxu Li and Qiang Dai contributed equally to this work. Correspondence and requests for materials should be addressed to Zejun Zhang (email: zhangzj@ioz.ac.cn) or D.Q. (email: qidunwu@163.com)
} 